\title{
HISTÓRIAS E MEMÓRIAS DA ESCOLARIZAÇÃO DAS POPULAÇÕES RURAIS: SUJEITOS, INSTITUIÇÕES, PRÁTICAS, FONTES E CONFLITOS
}

por Sandra Cristina Fagundes de Lima e Gilvanice Barbosa da Silva Musial. Jundiaí: Paco Editorial, 2016, 496 páginas. ISBN: 978-85-462-0663-6.

Compreender transformações, permanências e conflitos que envolvem a história dos processos educativos implementados em áreas rurais é um dos objetivos do livro intitulado Histórias e memórias da escolarização das populações rurais: sujeitos, instituições, práticas, fontes e conflitos. Os objetivos desse livro abrangem, ainda - recorrendo a palavras das organizadoras-, aspectos relacionados a escolas rurais e práticas educativas; legislação; representações e memórias sobre a educação, a escola rural e seus sujeitos; potencialidades das memórias e da literatura como fontes de pesquisa e aprofundamento teórico-metodológico em pesquisas que demandam novas habilidades para lidar com diferentes fontes.

Esse livro, organizado por Sandra Cristina Fagundes de Lima e Gilvanice Barbosa da Silva Musial, foi lançado em 2016 pela Paco Editorial e classificado no estrato L3 do Qualis Livros da Coordenação de Aperfeiçoamento de Pessoal de Nível Superior (CAPES). Totalizando 496 páginas e três seções — «Aqui... Minas Gerais», "Ali... Ceará, Rio Grande do Sul, Pernambuco, São Paulo» e «Em todo lugar... Mali, Portugal e Argentina»—, o livro é composto por 14 capítulos, escritos por 18 pesquisadores de diferentes Universidades, Estados e Regiões do Brasil, bem como de outros países e continentes.

São apresentados resultados principalmente de pesquisas relacionadas ao Grupo de Pesquisa em História do Ensino Rural da Universidade Federal de Uberlândia (Gpher/UFU) — pesquisas que contaram com financiamento da Fapemig/CNPq- e do Núcleo de Estudos e Pesquisas 
em História da Educação da Universidade do Estado de Minas Gerais (Nephe/UEMG).

Gilvanice Barbosa da Silva Musial, no capítulo «A literatura como fonte para o estudo da educação das populações rurais em Minas Gerais no final do século XIX», tem por objetivo analisar as potencialidades e os limites da literatura como fonte para o estudo da educação das populações de áreas rurais e discutir as possibilidades dessa fonte para a compreensão e registro das representações sobre os espaços sociais rurais, sobre seus sujeitos e sobre seus processos educativos. A autora analisa quatro romances — «O Caboclo», «A Capital», «O Mestiço» e «Morro Velho - do escritor sabarense Avelino Fóscolo, pois considera que esses livros permitem atingir o objetivo proposto nesse capítulo. Em relação aos espaços rurais, Fóscolo apresenta uma territorialidade marcada pela presença dos latifúndios, que congregam pequenas populações nos seus entornos, com igreja e casa de escola. Esses espaços têm por sujeitos majoritários populações escravizadas, bem como populações livres e pobres —negras, mestiças e brancas-. A educação dessas populações preteria a escola, ocorrendo por meio do trabalho, historicamente uma forma de disciplinar os grupos subalternos. Ressalta-se que, ainda que a escola rural não seja abordada, a educação perpassa os livros analisados pela autora.

Quais as condições de funcionamento das escolas públicas primárias rurais em Minas Gerais entre 1899 e 1911? Partindo desse questionamento, Josemir Almeida Barros, no capítulo «Escolas públicas primárias rurais em Minas Gerais: condições materiais e materiais pedagógicos em fins do século XIX e início do XX», tem por objetivo analisar o funcionamento da escola pública primária em áreas rurais no que se refere aos materiais pedagógicos e à infraestrutura. $\mathrm{O}$ autor ressalta que os materiais pedagógicos utilizados variavam conforme as diversas reformas, porém, nem sempre chegavam às escolas rurais. Nesse período era alarmante a insuficiência de materiais pedagógicos. Além disso, nas fontes analisadas constam diversas críticas em relação à infraestrutura das escolas, característica que impactava nas condições de ensino/aprendizagem. Esse período é marcado por ausências, descaso e desleixo do Poder Público em relação à escola rural. 
No capítulo «Novos tempos, discursos antigos: educação rural em Araguari na década de 1930», de autoria de Gilma Maria Rios, são analisados artigos publicados no jornal Gazeta do Triângulo e em algumas leis municipais sobre a questão da educação rural na localidade e no período delimitados. A autora menciona problemas recorrentes na educação rural araguarina, como por exemplo, dificuldades de acesso, longas e desconfortáveis viagens, hospedagens inadequadas e isolamento dos professores. Além disso, a educação não atingia a maioria das populações infantis em idade escolar naquela região. O Estado de Minas Gerais buscou adequarse às inovações que estavam ocorrendo na educação, implementando, em 1906, os Grupos Escolares, cuja criação, em Araguari, ocorreu em 1908. No entanto, essas inovações não foram lineares, simultâneas e não chegaram de maneira uniforme a todas as regiões. $\mathrm{O}$ acesso das populações de Araguari à escola elementar foi um processo lento.

Tânia Cristina da Silveira e Cristiane Angélica Ribeiro, no capítulo «O rural e o urbano nas atas de reuniões da Associação Comercial, Industrial e Agropecuária de Uberlândia (Aciub), 1933-1953», investigaram os discursos dos membros da diretoria dessa Associação, com vistas a compreender as representações e o papel das escolas e dos espaços rurais na consolidação de Uberlândia no período delimitado. A Aciub criou escolas rurais e promoveu outras "ações assistencialistas», entretanto, a promoção da educação das populações do campo despertou pouco interesse dessa entidade, o que expressa a visão dessa Associação acerca do campo, vinculado ao atraso, e da cidade, vinculada à modernização. A questão do rural era uma polêmica nessa Associação, que em 1969 passou a se chamar Associação Comercial e Industrial de Uberlândia, ou seja, o rural foi preterido, em conformidade com o objetivo de modernização da cidade, modernização essa expressa na opção pela industrialização.

«Prescrevendo práticas de higiene e saúde: os diários dos clubes de saúde do curso de aperfeiçoamento para professores rurais da Fazenda do Rosário - Ibirité-MG (1940-1956)» é o capítulo de autoria de Walquiria Miranda Rosa, que analisa, com base nos diários dos clubes de saúde e nas cadernetas de anotações das professoras/alunas, os cursos de aperfeiçoamento para professoras rurais, idealizados por Helena Antipoff e oferecidos, em regime de internato, na Fazenda do Rosário, entre 1948 e 1956. Um dos objetivos desse curso era o preparo das professoras rurais 
para a atuação e a difusão de meios que possibilitassem a preservação da saúde delas próprias, dos estudantes e da comunidade, além de prevenir doenças, por meio da adoção de práticas de hábitos de higiene. $\mathrm{O}$ curso tinha como um de seus princípios o método experimental e incluía exercícios práticos no clube de saúde e no clube agrícola. Dentre as disciplinas que compunham o curso, seis eram direcionadas à formação higienista, com o objetivo de ensinar as professoras, para que elas pudessem ensinar aos estudantes, hábitos higiênicos, em consonância com debates e políticas sobre a saúde no meio rural, a partir de uma perspectiva higienista, à época, recorrente no Brasil.

Sandra Cristina Fagundes de Lima, em «O rural, o silêncio, o esquecimento e o memorialista. Uberlândia-MG, 1950-1959», tem por objetivo problematizar as representações acerca do mundo rural — seus habitantes e suas escolas - constantes nos escritos do destacado memorialista Jerônimo Arantes publicados na revista Uberlândia Ilustrada, entre 1950 e 1959. O texto encontra-se dividido em quatro sessões, quais sejam: a) o trabalho dos memorialistas; b) o contexto da década de 1950; c) a análise dos conteúdos desse periódico; d) o rural na e para além da revista mencionada. Esse memorialista figurou como redator e editor da Uberlândia Ilustrada, tendo idealizado e produzido a maioria dos textos nela publicados. As representações constituídas e disseminadas nos escritos de Jerônimo Arantes tinham perspectiva urbanocêntrica. Assim, num município majoritariamente rural e agrícola, a questão do mundo rural, de seus habitantes e de sua escola não fazia, com exceções, parte dos temas debatidos. Lima ressalta que o silêncio e os esquecimentos em relação ao mundo rural são indicativos das disputas sobre a memória/história.

Em «Inventores de trilhas nas selvas da racionalidade funcionalista: professoras leigas e alunos das escolas rurais (Uberlândia-MG, 1950-1979)», de autoria de Sandra Cristina Fagundes de Lima, Danielle Angélica de Assis e Silvana de Jesus Gonçalves, o objetivo é, a partir de entrevistas com 17 pessoas, apresentar memórias e histórias, constituídas principalmente por professoras e estudantes, sobre as práticas e o cotidiano nas instituições rurais de ensino no município de Uberlândia, de 1950 a 1979. Com base no conteúdo das entrevistas e dos demais documentos analisados, as autoras estabeleceram sete categorias para analisar as seguintes questões: 1) Perfil, Ingresso na docência/escola e 
Formação; 2) Condições de trabalho; 3) Espaços e Tempos escolares; 4) Cultura material e Práticas; 5) Sociabilidade; 6) Significados da escola; 7) Avaliação do trabalho desenvolvido. As autoras chamam a atenção para a questão das representações equivocadas acerca da escola localizada em áreas rurais, bem como para a questão das professoras leigas e dos estudantes dessas escolas que, para as autoras, numa perspectiva certeauniana, precisam ser entendidos como "poetas de seus negócios» e «inventores de trilhas na selva da racionalidade funcionalista».

No capítulo «Vínculos familiares e comunitários na construção social dos professores leigos no meio rural», Fábio Garcez de Carvalho analisa a trajetória dos professores leigos rurais no processo de institucionalização da profissão docente em áreas rurais, considerando contextos e sujeitos do município de Icapuí (CE), no período de 1940 a 2000. Nessas áreas, desprovidas de agencias educativas formadoras de professores, predominavam as escolas domésticas, instaladas em residências e comumente dotadas de professores leigos. O autor aponta o apoio das famílias na implementação, na manutenção e no funcionamento das escolas domésticas, marcadas pela precariedade de infraestrutura e de materiais. Carvalho infere que a trajetória dos professores na área rural em questão foi construída nas escolas domésticas e ressalta a importância dos professores leigos para manutenção dessas escolas, «que teimavam em sobreviver em meio as carências» de diversas ordens.

José Edimar de Souza e Luciane Sgarbi Grazziotin, em «Processos de institucionalização de escolas públicas no meio rural. Novo Hamburgo-RS (1824-1939)», têm por objetivo, por meio de análise longitudinal em perspectiva historiográfica, registrar o processo de institucionalização da escola pública primária em Lomba Grande, um bairro rural de Novo Hamburgo, de forma a possibilitar o conhecimento do espaço e do tempo de implementação da escola nessa localidade. A história da escola em Lomba Grande está diretamente associada à história da imigração e da colonização do Estado do Rio Grande do Sul, bem como à história da comunidade evangélica luterana. A comunidade de Lomba Grande, desde seu início, reconhecia a importância da educação e criou formas de ensinar, de educar e de transmitir princípios considerados importantes para a formação das crianças. Os autores destacam, ainda, que nessa 
região as escolas, inicialmente particulares e de matiz religiosa, foram paulatinamente substituídas por escolas públicas «de improviso».

No capítulo denominado «Entre mangueiras e coqueiros: Grupo Escolar Dom Malan e a política nacional de educação rural (1949-1953)», Virgínia Pereira de Ávila, tem por objetivo reconstruir a história da primeira escola pública estadual (graduada) de Petrolina (PE), qual seja, o Grupo Escolar Dom Malan. Analisando a planta arquitetônica, datada de 1953, Ávila aponta que se trata de uma construção que previa, para a área externa, espaços para pomar, horta e outras atividades tipicamente agrícolas. A autora discorre sobre aspectos da história da educação em âmbito nacional, como por exemplo, o Plano de Desenvolvimento para o Ensino Primário e a importante atuação do professor Robert King Hall. Esse Grupo destacou-se na alfabetização de crianças e adolescentes de Petrolina e imediações. A autora aponta a consonância entre a arquitetura desse Grupo Escolar e o anseio da cidade em se tornar vanguarda de desenvolvimento no semiárido nordestino.

Rosa Fátima de Souza e Kamila Cristina Evaristo Leite, no capítulo intitulado «Prescrições para a prática docente: estratégias de uniformização do ensino primário nas escolas isoladas paulistas (Rio Claro, 1946-1966)», têm por objetivo contribuir para o avanço da produção de conhecimento sobre a formação de professores rurais. Para isso, as autoras analisam um total de 134 atas de reuniões pedagógicas dos professores das escolas isoladas localizadas em Rio Claro (SP). Segundo Souza e Leite, entre 1930 e 1960, as reuniões pedagógicas desempenharam importante papel, em especial no que se refere à prescrição de práticas educativas, de formação de professores e de tentativa de uniformização do ensino primário, pois nessas reuniões ocorriam, entre outras atividades, a tentativa de moldar, não sem resistências, as condutas do professorado. Assim, essas reuniões configuraram-se como importantes contribuições no processo de profissionalização do magistério de Rio Claro.

Anne-Marie Chartier, em "A infância de Hampâté Bâ, da escola corânica à escola dos colonos», analisa as memórias de Amadou Hampâté Bâ, que visa retratar as narrativas da sua infância, especialmente no que se refere aos aspectos educacionais, desafios e estranhamentos entre a cultura e a educação de seu povo e a educação propiciada na «escola dos brancos», isto é, dos colonizadores. O texto instiga a reflexões sobre 
a questão de diversas concepções de educação, significativamente divergentes entre si, em especial no que se refere à ênfase na oralidade ou na escrita, assim como às diferentes dinâmicas da "escola dos brancos», da «escola corânica» e da escola da vida. Dentre os apontamentos apresentados por Chartier destacam-se: a) a importância de se historicizar as análises sobre o sucesso e o fracasso escolar e a relação entre os níveis de estudos e os indicadores de futuras posições sociais; as memórias de Hampâté Bâ contribuem para a problematização dessas questões, em especial, no local e no período abordados; b) a relação de forças entre colonizadores e colonizados e o papel ambivalente da escola nessa relação; c) a questão da lucidez, haja vista que o mundo a partir e sobre o qual Hampâté Bâ escreve a sua própria história foi destruído, não pela colonização, mas pela Primeira Guerra Mundial e seus desdobramentos em diversos aspectos da vida, tanto individual quanto coletivamente.

«Escolas rurais na 1. ${ }^{a}$ República Portuguesa (1910-1926). Inquéritos exploratórios», de autoria de José António Afonso, aborda os impasses e constrangimentos enfrentados pelas escolas em áreas rurais durante a 1. ${ }^{a}$ República em Portugal e apresenta notas sobre temáticas debatidas, à época, nesse país. Entre essas temáticas estão: a centralidade da educação no discurso republicano; o dilema sobre a tendência agrícola ou industrial desse país; a questão do urbanismo; o problema da emigração e o grau de instrução dos emigrantes; a questão do território e do desenvolvimento local; os altos índices de analfabetismo; a visão idealizada do rural; a evasão de alunos devido à necessidade de trabalhar para ajudar a família; o dever «moral» do professor para com a higiene e a saúde; o debate sobre a especificidade de programas de ensino adaptados para as escolas rurais; a precariedade dos edifícios, dos mobiliários e dos materiais escolares; o método de ensino João de Deus; a defesa, por alguns setores, de uma escola regionalista (adaptada às necessidades regionais); a questão do ensino noturno; os salários em atraso; a escassez e o fechamento de escolas. Para Afonso, em Portugal, não teriam existido escolas rurais, «mas singelamente escolas em espaço rural».

Elisa Cragnolino, em «Las escuelas primarias en el campo tulumbano. Historias de construcción, apropriaciones y disputas en el norte de Córdoba (Argentina)», aborda, interdisciplinarmente e a partir das perspectivas das famílias campesinas, a questão dos processos de construção e 
de apropriação de escolas primárias rurais no norte da província de Córdoba, durante todo o século Xx. A autora tem por objetivo compreender o envolvimento dessas famílias com a escola, inclusive no que se refere a aspectos, tais como, aceitação, resistência, negociação, tensões e diversidades de interesses, bem como relações de poder e de classe presentes nas comunidades. Cragnolino entende as escolas rurais como espaços de relações sociais amplas, para além da aprendizagem escolar. A autora destaca, também, a representação da escola rural como "pobre escuelita rural» e a necessidade de se registrar o empenho da comunidade estudada na luta pela educação das crianças, inclusive com a manutenção financeira da escola. Cragnolino registra, ainda, a luta contra o fechamento e pelo direito das comunidades a terem escolas, independentemente da quantidade de estudantes, pois, como ressaltado por um campesino em seu depoimento, «si la escuela se cierra este lugar se muere».

Considera-se, portanto, que o livro apresenta dados de pesquisas inéditas e contribui, assim, para o preenchimento de lacunas existentes na história da educação rural, como apontam diversos autores. Trata-se de uma temática relevante e polêmica, tanto na perspectiva da história do tempo passado quanto na da história do tempo presente. Indicativos disso são as iniciativas, as disputas e os debates acerca da educação e das políticas educacionais destinadas aos povos do campo, em especial em eventos nacionais ou internacionais da História da Educação ou da Educação do Campo. Ainda no que tange à relevância, é importante reiterar que embora tenham desempenhado papel fundamental na alfabetização da ampla maioria das populações brasileiras, mais especificamente das crianças, as escolas rurais foram, segundo as organizadoras do livro, relegadas a um segundo plano.

Estudar as histórias e as memórias da escolarização de diferentes áreas rurais, bem como seus sujeitos, instituições, práticas, fontes e conflitos é importante para conhecer o processo histórico e as razões da atual configuração da educação escolar propiciada aos povos do campo, tanto no Brasil quanto noutros países. Pelo fato de apresentar dados de diferentes momentos históricos e localidades, o livro propicia dados e contribui, também, para estudos em perspectivas da história comparada.

Sem desconsiderar as especificidades em termos de, dentre outros fatores, sociedades, regiões, países, continentes, culturas e momentos 
históricos abordados no livro, constatam-se, para além das diferenças, diversas proximidades em termos de restrição, negação ou retrocessos no direito à educação, especialmente no que se refere à não abertura ou ao fechamento de escolas; aos estigmas em relação ao campo, suas populações, seus modos de vida ou culturas; a permanências históricas, tais como, morosidade, incipiência, descontinuidade e precariedade da educação escolar propiciada pelo Estado às populações de áreas rurais: Aqui..., Ali... e Em todo lugar... 